\title{
Regularização fundiária e requalificação urbana como foco do entrelaçamento entre os projetos de Engenharia Pública e de assistência jurídica universitária.
}

DOI: 10.37702/2175-957X.COBENGE.2021.3681

Pablo Rodrigo Fica Piras - pafipi@uefs.br

Universidade Estadual de Feira de Santana

Av. Transnordestina s/n

44036-900 - Feira de Santana - BA

LARIANA SALES SANTANA - santanalariana@gmail.com

UNIVERSIDADE ESTADUAL DE FEIRA DE SANTANA

AVENIDA ANTONIO RIBEIRO MARQUES 601

44073-100 - FEIRA DE SANTANA - BA

Ana Carolina Aguiar da Costa - carolcosta1991@hotmail.com

Universidade Estadual de Feira de Santana

Rua corinto 102

44090-292 - Feira de Santana - BA

Gustavo Vieira Gonçalves - gustavogoncalves_11@hotmail.com

Universidade Estadual de Feira de Santana

Rua Paranavaí 273

44054-056 - Feira de Santana - BA

ADRIANA NOGUEIRA VIEIRA LIMA - adriananvlima@gmail.com

UEFS

Rua Santa Rita de Cássia 78

40150-010 - Salvador - BA

Resumo: Como prática interdisciplinar em torno ao direito à moradia não realizado, o grupo PET Engenharias tem realizado aproximação com dois projetos de extensão na instituição, o Escritório de Engenharia Pública - EPTEC - e as alternativas que prestam atendimento jurídico na universidade: o Serviço de Assistência Judiciária - SAJ e o Núcleo de Prática Jurídica - NPJ, na medida em que essa colaboração é pertinente e necessária na hora de buscar a concretização do 
disposto no artigo 60 da Constituição Federal e na Lei 11.888/2008, que assegura ao cidadão a assistência técnica necessária no projeto e a construção de habitação de interesse social e a regularização urbana. Assim, esta aproximação também é consequência do acionamento por anos destas estruturas universitárias por parte de moradores da cidade, particularmente da Rocinha de Feira no bairro Lagoa Grande, o local escolhido para este recorte. No local, todo o conjunto de residências está em situação urbanística precária, moradias sem registro que ocupam uma área ambientalmente frágil, às margens da mencionada lagoa urbana, o que, como em outros casos na cidade, colide com as diretrizes ambientais, coloca os moradores em risco sanitário e afeta o usufruto coletivo dos recursos hídricos na cidade. Estas intervenções no ambiente construído, com aprofundamento das relações com moradores, apresentação do plano, coletando dados nas residências, quando autorizado, proporcionaram um vínculo com os requerimentos da área do Direito vis-à-vis as demandas da população, que não usufrui dos seus direitos com plenitude. Um passivo de várias centenas de solicitações não atendidas, sejam elas oriundas do SAJ ou da Defensoria Pública local, atenuam a eficácia desta tentativa de convergência destas iniciativas interdisciplinares universitárias, visando também a formação cidadã dos profissionais formados nela.

Palavras-chave: Interdisciplinaridade; Planta; Memorial; Assentamento popular espontâneo; Intelectual orgânico. 


\section{REGULARIZAÇÃO FUNDIÁRIA E REQUALIFICAÇÃO URBANA COMO FOCO DO ENTRELAÇAMENTO ENTRE PROJETOS DE EngeNHARIA PÚbLICA E dE ASSISTÊNCIA JURÍDICA UNIVERSITÁRIA.}

\section{INTRODUÇÃO}

Tradicionalmente, os cursos de Direito e Engenharia despertam interesse dos jovens que se preparam para a universidade: a admissão requer uma melhor preparação e seus graduados provavelmente serão melhor remunerados, além do prestígio social reservado às profissões liberais. Assim, a atuação profissional nesse campo tende a identificar-se somente com os valores hegemônicos da classe dominante, seja desde a visão do Direito como defesa do status, quanto a vinculação a uma Engenharia dedicada aos desafios melhor remunerados. Tanto as comunidades tradicionais e de agricultura familiar quanto os moradores das periferias das grandes cidades e outros segmentos de excluídos dos benefícios do modelo capitalista proporcionam realidades que naturalmente fortalecem a formação de intelectuais orgânicos (Antonio Gramsci, Cadernos do Cárcere, 1929 e 1930), que atuam na interconexão de classes ou grupos sociais distintos enquanto envolvem-se como educadores, tradutores e produtores da classe social que deles necessita, empoderando-se diante das instituições do Estado e da classe hegemônica. A regularização fundiária e requalificação urbana é uma das várias formas de potencializar essa convergência.

\section{OS PROJETOS EM COLABORAÇÃO}

\subsection{O Escritório de Engenharia Pública - EPTEC}

Assistência Técnica Gratuita à população de baixa renda começa a se desenhar como política pública, principalmente após a consumação de instrumentos legais como a Lei 10.257 de 2001 - Estatuto da Cidade, a Lei 11.124 de 2005 - que institui o Sistema Nacional de Habitação de Interesse Social e a mais recente Lei 11.888 de 2008, dentre outros. Na Bahia, há diversas instituições públicas e privadas engajadas na proposta: a Universidade Estadual de Feira de Santana (UEFS) estruturou o seu Escritório de Engenharia Pública - EPTEC.

Engenharia e Arquitetura contribuem significativamente com a tecnologia nacional, mas são também setores que apresentam uma enorme dívida social ao país, vis-à-vis o estado do acesso às estruturas urbanas e, principalmente, moradias.

Além de promover fóruns de debates e publicações, promover o uso racional da tecnologia e articular-se com outras instituições nacionais e internacionais, o EPTEC vem atuando em: (1) desenvolvimento de projetos e produtos acessíveis à população de baixa renda; e (2) apoio técnico a projetos de iniciativas comunitárias que visem à melhoria das condições de habitabilidade destas populações.

O público alvo do EPTEC é a população residente na Região Metropolitana de Feira de Santana em situação de reconhecida e comprovada carência, bem como instituições e entidades da sociedade civil, sem fins lucrativos, que solicitem trabalhos e projetos demandados nestas áreas do conhecimento. 


\subsection{Os serviços de assistência jurídica e a pesquisa neste campo.}

Entre os quase de duzentos projetos registrados, a UEFS tem dois projetos extensionistas cujas equipes desenvolvem trabalhos jurídicos e disponibilizam esse atendimento à população. Ambos se enquadram no que o Parecer CNE veio em 2014 a autorizar, à revelia da $\mathrm{OAB}$, que pretendia diminuir a abrangência de tais serviços à população (Mendonça et alii, 2013). Por um lado, o Serviço de Assistência Judiciária - SAJ está estruturado como um escritório, com estrutura administrativa e docente de apoio regular, profissionais contratados para as intervenções forenses. Pelo outro, o Núcleo de Pesquisas Jurídicas - NPJ o faz desde uma perspectiva em que as demandas se entendem como objeto de realização do vínculo no tripé universitário ensino-pesquisa-extensão. Até o momento, mesmo em uma proporção relativamente menor, se comparados aos processos de Direito de Família, o SAJ tem encaminhado alguns pedidos de usucapião ao EPTEC, ao longo dos anos recentes. Nisto, o SAJ soma-se às demandas que também encaminha a Defensoria Pública do Estado da Bahia, na aplicação do Direito positivo formal, e o NPJ se coloca de mais próximo do que se entende como o repertório analítico do campo crítico do Direito (Lima, 2019). Pois as irregularidades fundiárias e moradias precárias em moram uma parcela significativa da população brasileira são constatações imediatas que levam a confirmar a tese já estudada, do pluralismo jurídico, por oposição ao monismo jurídico, que "aposta do Estado como único produtor da norma jurídica, considerando que o Direito válido é apenas aquele produzido dentro dos trâmites do processo legislativo, independentemente do seu lastro de legitimação", como resposta "à negligência do Estado enquanto provedor de infraestrutura urbana, habitação e cultura nos territórios populares" (Lima, 2019).

\section{METODOLOGIA}

$\mathrm{Na}$ etapa de entrada, identifica-se o tipo do processo (usucapião, nova construção, reforma, ampliação, perícia ou levantamento topográfico) e são coletadas as informações sobre o assistido através de um questionário socioeconômico. Feito isso, o processo é registrado no banco de dados físico e virtual (baseado no Microsoft Access $®$ ) e entra na fila de espera. A fim de mecanizar essa coleta, foi criada uma planilha de dados anuais em EXCEL $®$ ligado diretamente ao banco de dados virtual de cadastro de projetos no Microsoft Access ${ }^{\circledR}$. Sendo assim, toda vez que o banco de dados virtual recebe uma nova informação, a planilha criada é atualizada. Tal vinculação permite consolidações que alimentam os relatórios que diferentes órgãos e instâncias solicitam (Figuras 1 e 2).

$\mathrm{Na}$ etapa de agendamento, o escritório solicita ao setor de transportes da Universidade o transporte até o local de realização da visita, comunicando também ao assistido sobre a data e horário do agendamento, além de passar algumas recomendações.

$\mathrm{Na}$ fase de visita, comparece ao local uma equipe composta por três estagiários (no caso de visitas periciais os estagiários são acompanhados por um responsável técnico), portando os equipamentos necessários. Durante a realização da visita, é feita a coleta de dados (medições, registro fotográfico). Ao retornar, registram-se as informações coletadas e é feita uma atualização da situação do processo nos arquivos do escritório, no software Access $\AA$ e na plataforma Asana®.

$\mathrm{Na}$ fase de produção, um ou mais participantes do EPTEC ficam responsáveis pela confecção dos documentos solicitados, supervisionados pelos responsáveis técnicos do 
escritório. Finalizada a produção, os projetos são revisados pela arquiteta e/ou pelo engenheiro civil residentes e encaminhados para a gráfica da universidade.

Com os projetos já revisados, o requerente do processo é comunicado e convidado a comparecer no escritório para a entrega, ocorrendo o posterior arquivamento do processo, também registrada em banco de dados físico e digital.

Figura 1 - Planilha organizada por Ano

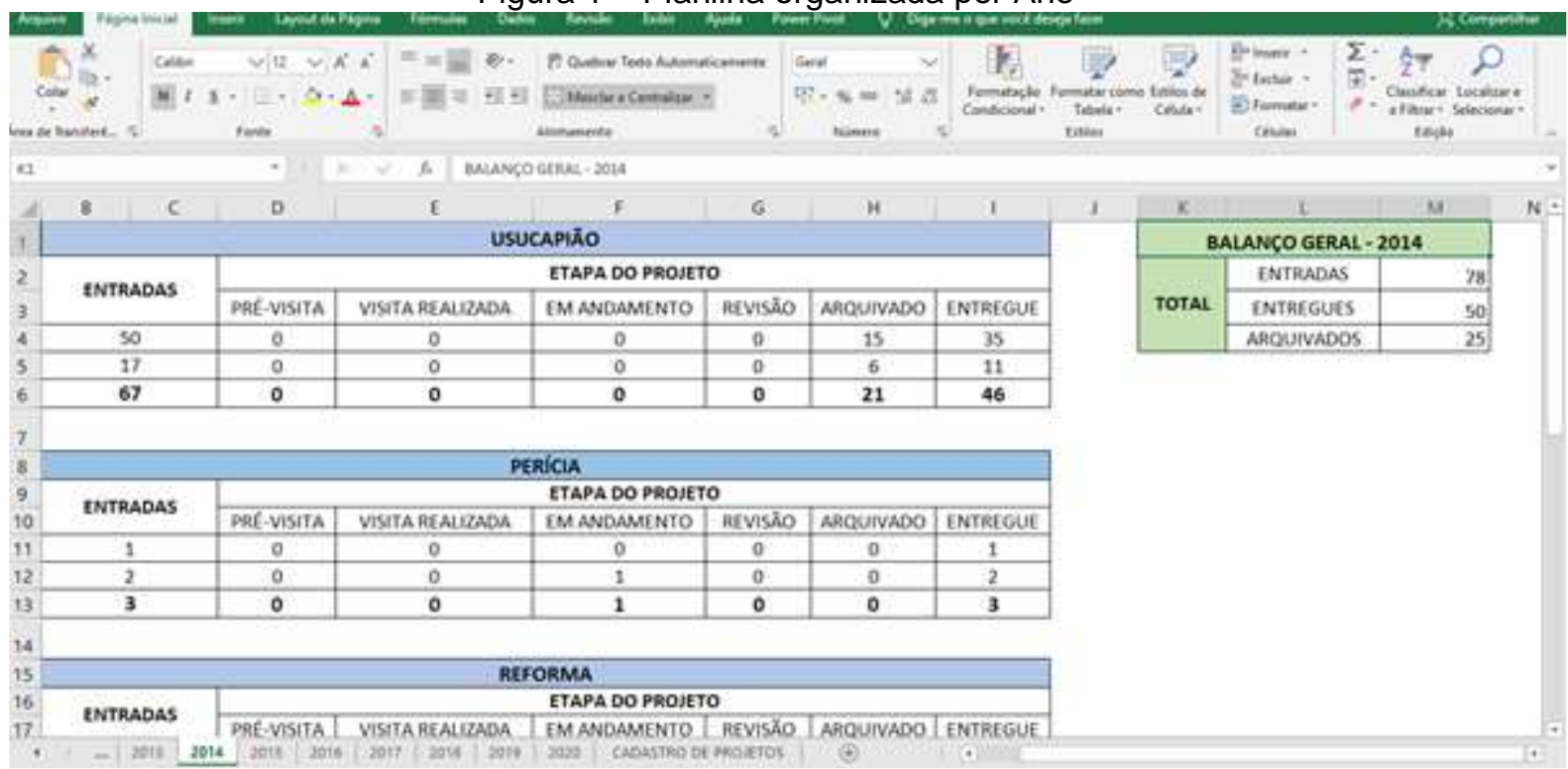

Figura 2 - Balanço geral do ano de 2014 fornecido pela planilha

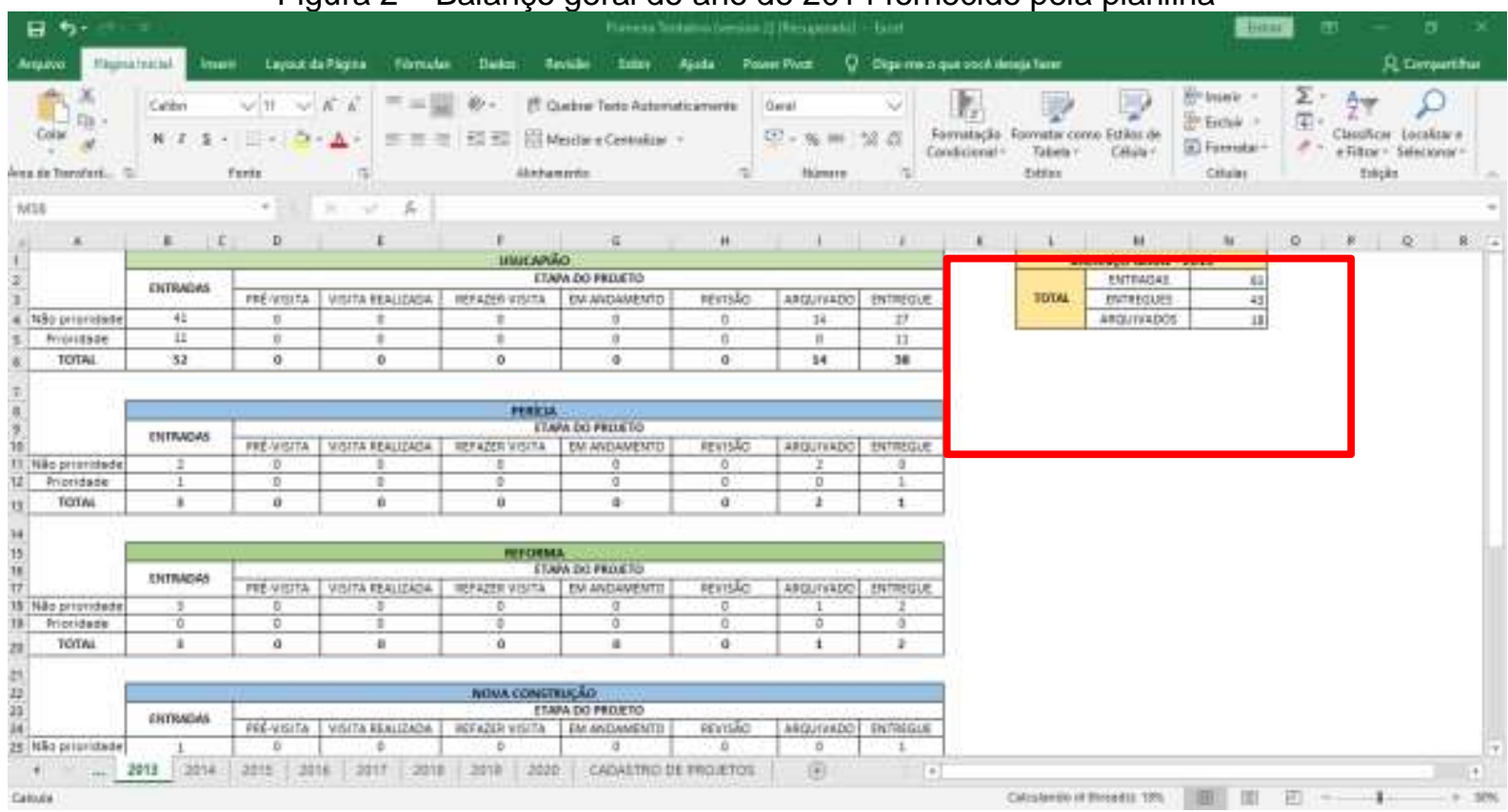




\section{RESULTADOS PRÉVIOS}

Como citado na caracterização dos processos, na etapa de entrada, identificaramse o tipo do processo (usucapião, construção, reforma ou levantamento topográfico) e são coletadas informações sobre o assistido, através de um questionário socioeconômico. Posteriormente, o processo, com todos os dados é registrado no banco de dados físico e virtual (baseado no Microsoft Access $\AA$ ) e entra na fila de espera.

Tem havido incompletitudes na coleta dos dados, que dificultam a avaliação do desempenho anual, principalmente no translado de dados anteriores originados em coleta e registro manual mediante contagem das pastas de processos. Um método lento e cansativo e que por vezes ocorreram erros durante a contagem.

Essa planilha organiza também o número de entradas em cada tipo de processo, e em que etapa o processo se encontra (pré-visita; visita realizada; refazer visita; em andamento; revisão; arquivado e entrega). Fazendo ainda um balanço geral do ano, com o número de entradas total e quantos processos foram entregues ou arquivados.

\section{CONTRIBUIÇÕES À REGULARIZAÇÃO FUNDIÁRIA EM FEIRA DE SANTANA}

Feira de Santana é um município que tem uma população estimada em 619.609 pessoas [IBGE, 2020] e uma área de $1.304,425 \mathrm{~km}^{2}$ [IBGE, 2019]. Apresenta um crescimento urbano desordenado e teve o surgimento de grandes assentamentos populares espontâneos, alguns deles nas margens das lagoas, em desacordo com as diretrizes ambientais nacionais, tanto porque as comunidades ali localizadas o fazem em condições estruturalmente precárias quanto porque tal avanço deteriora o usufruto dos recursos hídricos e o indisponibiliza para o restante da população.

Dos 44 bairros listados na divisão da região antes da última expansão, o bairro da Lagoa Grande é localizado na parte leste do centro de Feira de Santana, onde o sub-bairro da Rocinha, tem coordenadas geográficas $12^{\circ} 15^{\prime} 0^{\prime \prime}$ 'S latitude e $38^{\circ} 55^{\prime} 30^{\prime \prime} \mathrm{W}$ e $38^{\circ} 57^{\prime} 0^{\prime \prime} \mathrm{W}$ longitude, dentro do Anel de Contorno, com CASEB, Santo Antônio dos Prazeres, Parque Getúlio Vargas e Ponto Central como bairros vizinhos em seu entorno.

\subsection{O bairro Lagoa Grande}

Em 2008, o bairro Lagoa Grande foi contemplado com ações do Programa de Aceleração do Crescimento (PAC-2007-2010), através do projeto de requalificação urbana, que visava a recuperação de áreas degradadas, implementação de ações relacionadas à habitação, saneamento e inclusão social principalmente em áreas de assentamentos precários. Constata-se que, apesar das intervenções do PAC, ainda persistem áreas próximas à lagoa que têm situação crítica de infraestrutura, com o tecido urbano e com vias de circulação irregulares e sem pavimentação, com acentuados transtornos em períodos de chuva.

Esse bairro foi escolhido como o recorte inicial de estudo deste trabalho porque, além de abrigar um alto número de residências em situação precária e moradias irregulares, vem sendo há anos foco da dedicação do EPTEC, já que um conjunto de moradores dessa localidade tem acionado repetidamente o escritório. Esta trajetória e permite visualizá-lo como um conglomerado importante, mas com poucas condições de habitabilidade para seus moradores e um conjunto de ocupações de áreas ambientalmente frágeis. 
Ainda, do ponto de vista formal, como já mencionado, trata-se de uma área contemplada pelo programa nacional PAC, com projeto da CONDER, mas sem regularização fundiária até o presente momento. Em face à lei 13.465/2017, o presente plano também indaga a possibilidade de aproximar-se e estabelecer diálogo com a entidade associativa representativa do local, para concepção e eventual elaboração de etapas preliminares de um projeto de regularização, pois dita lei a habilita formalmente para requerer a regularização fundiária do local que representa.

Assim, ao realizar um trabalho sistêmico de elementos preliminares para a regularização fundiária da área irregular do bairro Lagoa Grande, o EPTEC pretende tanto contribuir nos aspectos técnicos relevantes e indispensáveis, como também entrelaçá-los com a compreensão dos aspectos socioeconômicos e de infraestrutura de saneamento que inevitavelmente os acompanham.

Pelo estado, complexidade, antiguidade e tamanho do caso da Lagoa Grande, espera-se que esta proposta tenha um impacto relevante e positivo para a população da área contemplada, tanto pelo processo de regularização como pelos demais requisitos de saneamento do lugar onde vivem, a caminho da concretização de um direito fundamental dos cidadãos brasileiros - o direito à moradia - e assegurar o cumprimento da função social da propriedade.

\section{CONSIDERAÇÕES FINAIS}

O trabalho que vem sendo desenvolvido tem como objetivo levar para a comunidade aquilo a que eles têm direito, porém perante ao estado sendo excluídos. O EPTEC converge no sentido de tentar cumprir o seu compromisso com a comunidade, na forma de benefícios realizando aquilo que os estudantes aprendem nos cursos, visando amenizar a desigualdade social através de ações concretas. O Escritório atende tanto demandas diretas como advindas dos órgãos de Direito em colaboração, como a Defensoria Pública e o SAJ-UEFS.

Estes trabalhos têm contribuído tanto a sanar limitadamente estas iniquidades sociais como também, de modo singular nos estudantes e professores participantes, no desenvolvimento/aprofundamento de tais habilidades, na interação direta das visitas e na confecção dos projetos.

Pois esta transição permanente, esta irregularidade fundiária e condições inadequadas para as moradias de uma parcela ampla da população urbana, constatações diretas que vem sendo realizadas no convívio com os moradores da Rocinha de Feira, levam a confirmar a tese já supramencionada, do pluralismo jurídico.

\section{REFERÊNCIAS}

Cartilha regularização fundiária urbana 2017. Disponível em: <https://www.sinoreges.org.br/Documentos/Upload_.Conteudo/arquivos/cartilha_regularizacao_fundiaria _urbana_2017.pdf>. Acesso em: 13 de set. de 2020.

Feira de Santana (BA) | Cidades e Estados. Disponível em: <https://www.ibge.gov.br/cidades-e-estados/ba/feira-de-santana.html>. Acesso em: 10 de set. de 2020. 
Gonçalves, C.W.P. Possibilidades e Limites da Ciência e da técnica diante da questão ambiental. s/l, Revista GEOSUL, n॰8. ano III, 1988.

Grostein, M.D. Metrópole e expansão urbana: A persistência de processos “ insustentáveis" São Paulo Perspec. vol.15 no.1 São Paulo Jan./Mar. 2001

Lima, A.N.V.. (2019). Do Direito Autoconstruído ao direito à cidade: porosidades, conflitos e insurgência em Saramandaia. Salvador: EDUFBA - PPG-AU FAUFBA. 304 p.

Manual PAC favela_23_08_07-revisado-V1. Disponível em:<http://aprece.org.br/wpcontent/uploads/2015/11/Manual_PAC_Favelas_2007_2010.pdf> Acesso em: 15 de set. de 2020 .

Mendonça, E.F.; Dorea, A.D.R.; Armonia, P.L.. (2013). Revisão do Art. 7ํ da Resolução CNE/CES no 9/2004, que institui as Diretrizes Curriculares Nacionais do Curso de Graduação em Direito e dá outras providências. Parecer CNE/CES no: 150/2013. Processo no: 23001.000024/2013-87.

PMFS- Prefeitura Municipal de Feira de Santana. Plano Diretor de Desenvolvimento Urbano de Feira de Santana, 2018

RD UFRB: Análise ambiental do entorno da Lagoa Grande em Feira de Santana, Bahia. Disponível em: <http://www.repositoriodigital.ufrb.edu.br/handle/123456789/1016>. Acesso em: 15 de set. de 2020.

Urbfavelas. III Seminário nacional sobre urbanização de favelas - Salvador - BA - Brasil. Urbanizar para integrar? Disponível em: <http://www.sisgeenco.com.br/sistema/urbfavelas/anais2018a/ARQUIVOS/GT1 264-215-20180820234318.pdf >. Acesso em: 13 de set. de 2020.

\section{LAND REGULARIZATION AND URBAN REQUALIFICATION AS A FOCUS OF THE INTERLACING BETWEEN PUBLIC ENGINEERING AND UNIVERSITY JUDICIAL ASSISTANCE SERVICE.}

Abstract: Here is analyzed the interlacing between two institutional extension projects, the Office of Public Engineering - EPTEC - and the Legal Assistance Service - SAJ, in articulation with the Tutorial Engineering group. These make interdisciplinary practices around the constitutional right to housing, not accomplished until now. Rocinha de Feira, in the Lagoa Grande neighborhood, was the chosen place, after some of its residents, for years, were been activating these university structures. These University offices exist in line with Article 6 of the Federal Constitution and Law 11888/2008, to ensure provide families with the necessary technical assistance in the project and the construction of social housing and urban regularization. At the site, the entire set of residences is in a precarious urban situation, unregistered homes that occupy an environmentally fragile area, on the margins of the aforementioned urban lagoon, which, as in other cases in the city, clashes with environmental guidelines, places residents at health risk and affects the collective use of water resources in the city. These interventions in the built environment, with deepening relations with residents, presentation of the plan, collecting data in the homes, when authorized, provide an approximation with the local requirements concomitantly with the 
demands of the population, who do not enjoy their rights fully. A liability of several hundred unanswered requests, whether they come from the SAJ or from the local Public Defender's Office, attenuate the effectiveness of the University's convergence with the citizen and interdisciplinary training of the engineering professionals trained in it.

Keywords: Interdisciplinarity; Plant; Memorial; Spontaneous popular settlement; Organic intellectual. 